\title{
0 receio de ser igual em meio às diferenças: reflexões acerca do antagonismo existencial dos professores do ensino médio diante da inclusão escolar
}

Claudia Terra do Nascimento Paz ${ }^{1}$ Yara da Rocha Cruz ${ }^{2}$

\begin{abstract}
Resumo:
Este trabalho objetivou observar o antagonismo existencial de professores do ensino médio da rede estadual de um município de Minas Gerais, em relação à educação inclusiva. Foram observados professores, lotados em cinco escolas da rede estadual, em um período de quatro anos (2016-2019), a partir do contato direto em espaços escolares informais, já que a autora atuou nessas escolas, em diferentes períodos. A partir de observações e memórias, foi organizada uma matriz observacional, que gerou documentação e registros, sendo possível identificar um deslocamento do antagonismo dos professores em relação à inclusão escolar, que passou da completa resistência inicial aos sentimentos de ansiedade e angústia. Pôde-se observar a empatia que os professores desenvolveram pelos alunos ao longo do tempo, o que corroborou ao desenvolvimento de sentimentos de angústia e de impotência. Em relação às expectativas docentes, as elas estão colocadas sob a necessidade de formação continuada. Assim, uma das opções para dirimir o antagonismo existencial dos professores é o fortalecimento da identidade e da formação docente, de forma a proporcionar suporte às práticas pedagógicas. Sem ter pretensão de ser conclusivo, observou-se que inclusão escolar não trata de cumprir legislação, mas de respeitar as particularidades dos sujeitos envolvidos no processo.
\end{abstract}

\section{Palavras-chave:}

Inclusão escolar. Estudantes com deficiência. Antagonismo existencial.

\footnotetext{
1 Pedagoga. Psicopedagoga. Educadora especial. Doutora em Educação na linha de Psicopedagogia e processos de ensino-aprendizagem pela UFRGS. Docente efetiva do IFSC, Campus Tubarão. E-mail: claudia.paz@ifsc.edu.br. ORCID iD: http://orcid. org/0000-0001-8182-9264.

2 Graduação em Ciências Sociais. Licenciatura e Bacharelado pelo Centro de Ensino Superior de Uberaba CESUBE. Pós-graduada em Educação de Jovens e Adultos (IFTM). Teoria Psicanalítica (UNIUBE) e Especialização em Educação Profissional e Tecnológica Inclusiva (IFTM). Docente na Escola Estadual Frei Leopoldo Castelnuovo, Uberaba, MG. E-mail: yararoch@gmail.com. ORCID iD: http://orcid.org/0000-0002-5244-6739.
} 


\title{
The fear of being equal in the midst of differences: reflections on the existential antagonism of high school teachers in the face of school inclusion
}

\begin{abstract}
:
This study aimed to observe the existential antagonism of high school teachers from the state network of a municipality in Minas Gerais, in relation to inclusive education. Teachers working in five schools in the state network were observed over a period of four years (2016-2019), from direct contact in informal school spaces, as the author worked in these schools, in different periods. From observations and memories, an observational matrix was organized, which generated documentation and records, making it possible to identify a shift in teachers' antagonism towards school inclusion, which went from complete initial resistance to feelings of anxiety and anguish. It was possible to observe the empathy that the teachers developed for the students over time, which corroborated the development of feelings of anguish and powerlessness. In relation to teacher expectations, they are placed under the need for continuing education. Thus, one of the options to resolve the existential antagonism of teachers is to strengthen their identity and teacher education, in order to provide support for pedagogical practices. Without claiming to be conclusive, it was observed that school inclusion is not about complying with legislation, but respecting the particularities of the subjects involved in the process.
\end{abstract}

\section{Keywords:}

School inclusion. Disabled students. Existential antagonism.

\section{El miedo a la igualdad en medio de las diferencias: reflexiones sobre el antagonismo existencial de los docentes de secundaria ante la inclusión escolar}

\begin{abstract}
Resumen:
Este estudio tuvo como objetivo observar el antagonismo existencial de los docentes de secundaria de la red estatal de un municipio de Minas Gerais, en relación a la educación inclusiva. Se observó a los docentes que trabajan en cinco escuelas públicas durante un período de cuatro años (2016-2019), desde el contacto directo en espacios escolares informales, ya que el autor trabajó en estas escuelas en diferentes períodos. A partir de observaciones y recuerdos, se organizó una matriz observacional, que generó documentación y registros, lo que permitió identificar un cambio en el antagonismo de los docentes hacia la inclusión escolar, que pasó de una total resistencia inicial a sentimientos de ansiedad y angustia. Se pudo observar la empatía que los docentes desarrollaron por los estudiantes a lo largo del tiempo, lo que corroboró el desarrollo de sentimientos de angustia e impotencia. En relación a las expectativas de los docentes, se ubican bajo la necesidad de una educación continua. Así, una de las opciones para resolver el antagonismo existencial de los docentes es fortalecer su identidad y formación docente, con el fin de brindar apoyo a las prácticas pedagógicas. Sin pretender ser concluyente, se observó que la inclusión escolar no se trata de cumplir con la legislación, sino de respetar las particularidades de los sujetos involucrados en el proceso.
\end{abstract}

Palabras clave:

Inclusión escolar. Estudiantes discapacitados. Antagonismo existencial. 


\section{Introdução}

O termo inclusão, de acordo com Mendes (2017, p. 61), refere-se ao “[...] ato ou efeito de incluir, o que significa pôr ou estar dentro, inserir ou fazer parte de um grupo; abranger, compreender, conter ou ainda envolver, implicar". A esse termo genérico, podemos agregar especificações como inclusão escolar.

Assim, quando associada ao processo de escolarização, temos a expressão inclusão escolar. Tal expressão foi popularizada pela Declaração de Salamanca (UNESCO, 1994), assumindo a compreensão de "escola para todos", em referência ao conjunto de estudantes que vêm sendo tradicionalmente excluídos da escola, considerando, então, todo e qualquer estudante como aluno da escola regular.

O princípio que orienta esta Estrutura é o de que escolas deveriam acomodar todas as crianças independentemente de suas condições físicas, intelectuais, sociais, emocionais, linguísticas ou outras. Aquelas deveriam incluir crianças deficientes e superdotadas, crianças de rua e que trabalham, crianças de origem remota ou de população nômade, crianças pertencentes a minorias linguísticas, étnicas ou culturais, e crianças de outros grupos desavantajados ou marginalizados (UNESCO, 1994, p. 3).

Nesse sentido, pensar a inclusão escolar implica pensarmos uma escola para todos; uma escola capaz de adotar estratégias de acessibilidade que possibilitem o acesso e a permanência de todos os alunos. Até aqui, pensamos o processo de inclusão escolar olhando para os estudantes. Mas e quando olhamos para esse processo da perspectiva dos professores?

Diversas são as pesquisas sobre as dificuldades e apreensões a respeito da atuação dos professores no processo da inclusão escolar na escola regular. Como exemplos, podemos citar o estudo de Konkel et al. (2015), que investigou as dificuldades no processo de inclusão educacional no ensino regular a partir da visão dos professores do ensino fundamental de uma escola pública em Santa Catarina. Outro exemplo é o estudo de Braga (2012), que investigou as dificuldades encontradas no ambiente escolar para a inclusão de crianças com deficiências. Também Sala, Moreno e Duarte (2020), investigaram as dificuldades relacionadas à inclusão escolar em uma escola de tempo integral, especificamente no que tange ao atendimento educacional especializado. E, como esses, vários outros exemplos poderiam ser citados.

Seja na teoria ou na prática, a questão do atendimento a estudantes com deficiências apresenta fatores dissonantes, que acabam por ocasionar insegurança no trato e desenvolvimento das ações propostas na sala de aula regular, especialmente pela percepção dos professores. Apesar dos avanços no atendimento desses alunos, tal processo ainda apresenta resultados tímidos no domínio necessário para o desenvolvimento de habilidades e competências no exercício da função, o que ocasiona temeridade por parte dos professores da sala de aula regular.

Não é difícil se deparar com professores que afirmam não terem sido preparados para atuar com este público ou que sua formação principal não é esta. E, mesmo, quando se trata de professores recentemente formados, em que na grade curricular do seu curso consta alguma disciplina dirigida à inclusão escolar, a fragilidade não é diferente.

Transcorridas quase três décadas desde as primeiras contextualizações sobre o atendimento na sala de aula regular dos estudantes com deficiências e as suas especificidades, observa-se que professores ainda estão temerosos e encontram dificuldades com tais propostas. Então, qual seria a melhor forma de atuar com esses alunos no ensino médio regular? Uma situação que provoca momentos sensíveis e antagônicos existenciais nestes profissionais, algo que trafega entre "o que devo ser" e "o que quero ser". 
O antagonismo existencial pode ser compreendido como um sentimento de oposição ou ausência de compatibilidade de opiniões e de perspectivas (CUNHA; CINTRA, 2001). No caso deste estudo, sentimentos estes vinculados ao processo de inclusão escolar, por parte de professores que fazem parte deste mesmo processo. Quando refletimos, no estudo, a respeito do antagonismo existencial dos professores, estamos falando sobre como esses professores se sentem em relação ao processo que está sendo estudado, e não tendo um juízo de valor a respeito do processo em si.

O conceito de antagonismo existencial deriva da corrente filosófica do existencialismo. A existência humana é o principal objeto de investigação da filosofia existencialista, como o próprio nome já indica. Na visão dos existencialistas, os indivíduos vão construindo seus próprios caminhos e suas concepções de vida no decorrer de suas existências. Neste processo de constante busca, a ausência de respostas satisfatórias aos indivíduos, gera o que os filósofos chamam de angústia existencial, que pode, por sua vez, gerar o antagonismo existencial (ABBAGNANO, 2007).

Nesse sentido, o objetivo deste estudo foi observar o antagonismo existencial de professores do ensino médio da rede estadual de um município de Minas Gerais, em relação à educação inclusiva. Foram observados professores lotados em 05 (cinco) escolas da rede estadual, durante um período de quatro anos (2016-2019), a partir do contato direto com esses docentes nos espaços escolares informais, tais como sala de professores e corredores, tanto nos intervalos de aulas como nos recreios e nas reuniões pedagógicas, já que a autora do estudo atuou nessas cinco escolas, em diferentes períodos. É interessante observar que é justamente nesses espaços que ocorrem os relatos mais sinceros, já que não estão sob a ótica de julgamentos e juízos de valor. A partir de observações e memórias, registradas em diário de campo, gerou-se uma matriz de análise qualitativa, através da qual foi possível realizar o referido estudo.

Ocorre que, ao mesmo tempo em que existe uma função a ser cumprida, a questão legal do direito à inclusão, coexiste a temeridade, e aí reside o antagônico, de acordo com a referida autora. Ainda que o professor se utilize de criatividade e "outras alternativas", deve cumprir sua função. Mas, na prática, não é tão simples.

A escola se entupiu do formalismo da racionalidade e cindiu-se em modalidades de ensino, tipos de serviços, grades curriculares, burocracia. Uma ruptura de base em sua estrutura organizacional, como propõe a inclusão, é uma saída para que a escola possa fluir, novamente, espalhando sua ação formadora por todos os que dela participam (MANTOAN, 2005, p. 15).

Ainda de acordo com Mantoan (2005, p. 35), paralelamente, existem “[...] interpretações tendenciosas de nossa legislação educacional e preconceitos distorcem o sentido da inclusão escolar, reduzindo-a unicamente à inserção de alunos com deficiência no ensino regular". Soma-se a isso a questão de que nas escolas estaduais de Minas Gerais não existe uma equipe multidisciplinar, quando muito o Atendimento Educacional Especializado (AEE). Daí, se pensar e refletir que existe no professor a ansiedade de como se colocar neste universo, que atualmente não se trata apenas de transmitir conteúdos, mas a necessidade de desenvolver competências para lidar com o diferente, como um processo de isonomia, de equidade e de direito fundamental e social.

No entanto, ainda que os professores do ensino médio regular não estejam se sentindo preparados para lidar com este universo, a empatia para com outro emerge, a percepção de que os sujeitos merecem a conquista de um espaço e o direito de desenvolverem suas habilidades. Um respeito às diferenças e a diversidade torna-se latente e imprescindível, bem como a inserção deste sujeito na sociedade como cidadão, passíveis de direitos e também de deveres de acordo com sua competência, e o fato de que, ter uma deficiência não implica incapacidade, daí sua inclusão no ensino regular.

Empatia não é necessariamente simpatia. Sobre esse ponto, Goleman (2013) afirma que a empatia passa pela compreensão dos próprios sentimentos, para se conseguir compreender o 
sentimento de outros. Dito isso, fica claro observar que, se ver no outro, muito tem de si mesmo. Ainda dentro desta teoria, ocorre que os mesmos circuitos cerebrais que nos fazem pensar sobre nós mesmos, nos permitem ter este mesmo olhar para o outro, lembrando que este outro tem sentimentos próprios, desejos e motivações, assim como "eu", como ser (GOLEMAN, 2013).

Se um professor acredita que sua tarefa é simplesmente transmitir os conteúdos ou, como se diz, "dar" matéria, resta muito pouco à sua criação: vai se utilizar apenas do livro didático e dará aulas expositivas nas quais se esforçará para apresentar, o mais claramente possível, o conteúdo que quer [ou pensa] que seus alunos aprendam (WEISZ; SANCHEZ, 2002, p. 117).

Isto não é um processo empático, mas mecânico. "A empatia exige um ato de autoconsciência: lemos os outros ao nos conectarmos com nós mesmos", como colocado por Goleman (2013, p. 105).

Assim como qualquer aluno, os professores não aprendem no vazio. Por isso, a proposta de formação parte do "saber fazer" desses profissionais, que já possuem conhecimentos, experiências e práticas pedagógicas ao entrar em contato com a inclusão ou qualquer outra inovação educacional (MANTOAN, 2003 p. 83).

Faz tempo que a questão de novos modelos de ensino-aprendizagem vem sendo discutida, bem como a formação continuada de professores. Pode-se partir do princípio de que não é falta de competência do professor, mas o modo de como exercer sua prática. Esta deveria insurgir através da construção de uma identidade docente real, e não tão somente por regras, que por vezes estão embasadas apenas na apresentação de resultados que contribuam para alimentar índices de "eficácia" do sistema (TARDIF, 2012).

Ao dizer isso, não significa que ao longo das últimas décadas não tenham sido desenvolvidas pesquisas e realizadas formações de professores, dentre outras ações que apresentam diversos métodos e técnicas de aprimoramento, tendências que perpassam caminhos entre a racionalidade e atitudes reflexivas. No entanto, existem algumas questões que permeiam a docência e essas estão interligadas às relações humanas, a interatividade próxima entre dois seres - professor e aluno - e, por vezes, esta proximidade implica um tráfego de sentimentos e sensações.

Então, quando se pensa na questão da empatia, também se pode pensar naquilo que nos molda. Cortella (2018) coloca isso muito bem ao citar o artista Michelangelo: "Todo pintor pinta a si mesmo". Ou, ainda, quando vem à lembrança uma das frases célebres do mesmo artista sobre um de seus trabalhos, de como fizera a escultura de Davi (com quase 4,5 metros em um só bloco de mármore): "Foi fácil, fiquei um bom tempo olhando o mármore até nele enxergar o Davi. Aí, peguei o martelo e o cinzel, e tirei tudo o que não era Davi!”.

Ou seja, são dois lados, duas formas de enxergar ou lidar com as coisas que se apresenta no viver e na prática do exercício profissional, ambas inerentes à mesma pessoa. Notem que Michelangelo olha para dentro de si ao mesmo tempo em que enxerga o que seria o outro. Isto faz emergir a expressão de sua empatia.

Nesse sentido, estamos mais uma vez vivendo um processo de ruptura de paradigmas, que se configura por uma nova percepção em lidar com outro, em que se torna necessário ver a si mesmo e, mais do que isso, ver além de.

Porém, uma coisa é o discurso, outra é a complexidade das relações, a mudança de comportamento quando a sociedade divide as pessoas entre normais e deficientes, em que até pouco tempo os sistemas escolares também apresentavam uma lógica organizacional marcada por uma visão determinista, mecanicista, formalista, que ignorava o subjetivo e alimentava um velho modelo de ensino.

Vale dizer que muitos dos professores estão imersos nesta doutrina, ainda que pensem que não, e, assim, temem ou não se consideram capazes de atender alunos que apresentem alguma 
diferença, seja por questões culturais, sociais, afetivas ou algum tipo de deficiência. Isso causa uma crise, crise essa que reforça o antagonismo existencial: do querer fazer com o como fazer (MANTOAN, 2005).

Sob esse aspecto, os professores também acabam por passar por um processo "excludente" junto aos seus pares. A questão proposta neste trabalho não é contrária à inclusão e seus benefícios, antes pelo contrário, procura observar que tal processo não afeta tão somente os alunos, mas também os professores, como atores ativos do mesmo, além do fato de serem tão humanos como aqueles que atendem, e que, portanto, apresentam em si fragilidades, e daí como tratar o diferente como igual sem ser indiferente, ou, ainda, ser igual em meio às diferenças.

Perrenoud (1999) já escrevia a respeito das estratégias de mudança, a transformação da formação dos docentes e a teorização do aprendizado e do ensino, navegando pela questão das competências, em que diz:

O mais difícil não é compor com as ideologias de uns e de outros, e sim trabalhar sobre as verdadeiras resistências à mudança, tão racionais, mas menos confessáveis. Não é irracional preservar interesses adquiridos, mesma que seja difícil confessar sua oposição a uma reforma porque ela complica a sua vida, dá muito trabalho, põe em evidência certas incompetências, ameaça o frágil equilíbrio construído com os alunos ou com os colegas, obriga a lutos insuportáveis, afasta das razões que levam a ensinar ou reanima velhas angústias iniciais. E, entretanto, o que se deveria ousar e poder dizer, para trabalhar a partir dessas reações muito razoáveis. Quem seria louco o bastante para contribuir com uma mudança que arriscasse colocá-lo, pessoalmente, em dificuldade? (PERRENOUD, 1999, p. 84-85).

Entenda-se, não se trata de uma simples resistência, ainda que Perrenoud (1999) coloque isso como normal no processo das competências, porém conseguir harmonizar uma sensatez que vai além do desejável, não através de uma imposição legal, mas antes, sim, pelo aprendizado, como ele mesmo cita: “[...] aprender, fazendo o que não se sabe fazer" (PERRENOUD, 1999, p. 58). Ou seja, aceitar a incompletude como uma característica inerente a qualquer um, seja aluno ou professor.

\section{Metodologia}

Este estudo desenvolveu-se através de um conjunto de reflexões, a partir de observações, registros e memórias, sem ser conclusivo, sobre o antagonismo existencial de professores do ensino médio regular, no que diz respeito à inclusão escolar, lotados em 05 (cinco) escolas da rede estadual de um município de Minas Gerais. A observação se deu em um período de quatro anos (2016-2019), a partir do contato direto com os professores do ensino médio, nos espaços escolares informais, tais como sala de professores e corredores, tanto nos intervalos de aulas como nos recreios e nas reuniões pedagógicas, já que a autora do estudo atuou nessas cinco escolas, em diferentes períodos. Já a análise de dados, ocorreu a partir dos registros e da documentação dessas observações, a partir de matriz qualitativa observacional.

Trata-se de uma pesquisa qualitativa, de tipo descritiva e observacional, que, apesar de ser motivada pela vivência, tem seu aporte teórico fundamentado em uma revisão de literatura, com autores que discutem as questões ideárias educacionais, sociológicas e filosóficas, sobre aspectos vivenciais do ser humano, como: Demo, Mantoan, Goleman, Barros Filho, Cortella, dentre outros.

"Os estudos observacionais fundamentam a possibilidade de descrição e compreensão do funcionamento do espaço natural, além da identificação de comportamentos que podem ser categorizados, revelando detalhes da interação pessoa-ambiente" (ALVES et al., 1999. p, 293). De forma a auxiliar no entendimento do fenômeno do qual trata este estudo, a compreensão da inclusão escolar foi embasada em uma reflexão sobre o antagonismo existencial do professor, apesar das 
propostas legais e político-pedagógicas. Ou seja, a percepção do professor, também ator e "parte" deste processo. Uma perspectiva sobre a questão do lidar, interagir com um novo paradigma no trato com pessoas com deficiência, algo que vai além de um conteúdo específico.

É neste ponto que a pesquisa acaba por se tornar uma reflexão, na medida em que mostra uma faceta existencialista do profissional/professor, como ser e seus questionamentos diante daquilo que acredita ter de fazer como uma ação a ser cumprida, até pela importância da inclusão no espaço escolar, ao mesmo tempo em que não sabe como fazer. Um questionamento que se manifesta pela busca de como proceder diante de uma ação que deveria ser gratificante para os envolvidos no processo.

Para tanto, utilizou-se da observação direta, definida por Batista (1996) como aquela em que o fenômeno é observado sem o auxílio de instrumentos. No entanto, "[...] todo trabalho em que se utiliza a observação como um instrumento de coleta de dados, [...] requer do pesquisador uma série de decisões" (CORDAZZO et al., 2008, p. 427). Deve-se definir, então, de acordo com Cordazzo et al. (2008), quem e o que será observado, onde será feita a coleta dos dados e como estes serão registrados.

Neste estudo, foram observados professores do ensino médio regular da rede estadual de ensino de Minas Gerais, sendo observado o antagonismo existencial dos professores em relação à inclusão escolar, a partir dos registros e da documentação das observações e memórias da autora. A coleta de dados, via observação direta do campo, e a análise deram-se a partir dos registros e documentações das observações, tendo como base uma matriz observacional, a partir da qual os dados foram registrados descritivamente em um diário de campo e analisados posteriormente, com base na referida matriz.

A matriz observacional deste estudo foi definida a partir de três aspectos, descritos a seguir:

1. Caraterização dos espaços escolares observados, especialmente no que tange às condições de acessibilidade necessárias à inclusão escolar;

2. Caracterização do antagonismo existencial dos professores diante da inclusão escolar e de seus deslocamentos ao longo do tempo;

3. Caracterização das expectativas docentes em relação à inclusão escolar.

Durante as observações, os seguintes questionamentos se fizeram presentes: $\mathrm{O}$ que ocorre quando o professor se torna refém de sua própria identidade? $\mathrm{O}$ antagonismo existencial se dá quando precisa-se realizar um processo de adaptação para uma realidade para a qual não foi preparado? Em que medida o sistema engessado ou doutrinador que existiu e ainda existe, em larga medida, contribui para o antagonismo existencial desses professores? Como esse antagonismo se desloca ao longo do tempo? Há, com o tempo, o comprometimento com o ensino e a aprendizagem dos alunos e sua formação profissional?

Durante as observações, apareceram sentimentos de ansiedade e apreensões, aspectos preocupantes para o desenvolvimento e aplicação das políticas públicas de inclusão, tornando-se necessário buscar caminhos e auxiliar efetivamente aos professores, além de responder suas questões, sem romantismos, mas através de ações que venham a contemplar suas expectativas em relação à educação inclusiva e, dessa forma, dirimir suas dúvidas e ansiedades.

\section{Apresentação e discussão dos resultados}

\section{Caracterização dos espaços escolares em relação à inclusão}

Iniciamos a apresentação dos resultados a partir da descrição dos espaços escolares, tanto no que se refere à estrutura física quanto aos aspectos educacionais pedagógicos e ao atendimento aos alunos com deficiências, em relação ao processo de inclusão escolar e suas demandas. 
As instituições em foco, como a maioria, no contexto das escolas da rede estadual de ensino de Minas Gerais, possuem um espaço físico bom, quadra de esportes, teatro de arena, anfiteatro, pequenas hortas para atender a demanda da instituição, sala de informática, bibliotecas, e, em algumas, laboratório de ciências. No entanto, não possuem uma estrutura adequada dentro dos padrões referenciados pela legislação em relação à questão da remoção das barreiras atitudinais, arquitetônicas e sensoriais, sejam rampas, mobiliário ou equipamentos.

Nota-se que com o passar dos anos não ocorreram transformações ou adaptações que evidenciem uma atenção especial com o atendimento aos estudantes com deficiências, nem ao menos em relação a um local específico para os profissionais de AEE, que geralmente utilizam um pequeno espaço nas bibliotecas ou nos laboratórios. Podem-se citar como exemplos: o piso tátil praticamente inexiste; $\mathrm{o}$ atendimento aos alunos com deficiência visual é precário; os alunos surdos não contam com o apoio de intérpretes de libras e somente alguns professores conseguem interagir com eles.

Outro detalhe é que as instituições de ensino regular não contam com profissionais das áreas de psicologia ou assistência social, apesar da demanda, ainda que realizado processo de classificação para uma possível designação. Cabe colocar que essas instituições são de porte médio e oferecem ensino fundamental I e II, ensino médio regular, EJA (Educação de Jovens e Adultos) e duas também oferecem Magistério.

Nesse sentido, as instituições cumprem sua função pedagógica e socioeducativa dentro dos limites de suas dimensões e possibilidades no atendimento de sua clientela, sem grandes privilégios, tentando desenvolver um trabalho de ruptura de barreiras e de inclusão de forma criativa e colaborativa através dos seus profissionais, o que acaba por ocasionar ou reforçar um antagonismo existencial, sobre: "O que é minha obrigação?", “O que posso fazer para ser melhor?" ou “Como vou conseguir isto?". Questões que em princípio são simples, mas que no dia a dia se tornam complexas, à medida que o professor não vislumbra resultados positivos ou não consegue desenvolver e promover as habilidades e competências dos seus alunos, em especial aqueles que apresentam deficiências.

\section{Caracterização do antagonismo existencial docente em relação à educação inclusiva}

No caminhar deste trabalho, foi possível visualizar um deslocamento do antagonismo dos professores em relação à inclusão escolar. De início, observava-se apenas uma resistência total ao paradigma inclusivo. Com o passar do tempo, especialmente na medida em que os professores construíram vínculos afetivos e empáticos com os alunos, os sentimentos migraram para angústia, ansiedade e, até mesmo, para a impotência, que paralisa.

Nesse sentido, os dados acabam por revelar questões existenciais, que podem ser compreendidas ao buscar alento nos filósofos existencialistas, em que o comportamento antagônico do ser surge na medida do questionar, sendo que seria mais fácil ser passivo diante do que se apresenta e tão somente cumprir o lhe é solicitado sem abrir lacunas, fazer apenas o que é proposto. No entanto, quando o ser interior se posiciona diante do que lhe toca, pela empatia ocasionada pelo outro, uma crise se instala, e o que deveria ser uma ação objetiva daquilo que se deve fazer, transforma-se em um processo de desorientação, ocasionado pelos questionamentos. "Todo questionamento é uma procura. Toda procura retira do procurado sua direção prévia. Questionar é procurar cientemente o ente naquilo que ele é e como ele é" (HEIDEGGER, 2005, p. 30).

Então, se a situação faz emanar questionamentos sobre aquilo que deve ser cumprido, a insegurança, a angústia e a expectativa se instalam, restando buscar respostas, como profissional/professor, sobre o meio que possibilitará "ser" sem perder o que se "é". Ainda de acordo com Heidegger (2005, p. 41), "[...] deve-se colocar a questão do sentido do ser. Com isso nos achamos diante da necessidade de discutir a questão do ser tocante aos momentos estruturais”. E, mais, Heidegger (2005), ainda 
diz que o agir que conhecemos é a reprodução de um efeito de acordo com a utilidade, mas que agir tem como essência o consumar, que por sua vez seria o pleno desdobrar de algo.

Assim, a probabilidade de desenvolver ações que não sejam apenas funcionais e normativas, seja possível não somente pela concordância ou aceitação do imposto, mas, sim, pela importância da questão, neste caso, a inclusão, que vai além da necessidade. E para que seja verdadeiro seu desenvolvimento, perpassa por diversas questões, dentre elas, o duplo sentido dos sentimentos, que, por vezes, se antagonizam para que ocorra a plenitude.

Isso porque, apesar das diferenças, existem fatores que coincidem com o interesse comum sobre a questão da educação, e de seus princípios de isonomia e de inclusão. Todos na escola, de algum modo, estão envolvidos, e, em princípio, possuem a vontade de que o processo seja proveitoso, apesar dos percalços e da complexidade de todo o sistema.

Por tudo isso, temos de ficar cada vez mais atentos, questionando o que existe, mas, ao mesmo tempo, apresentando outras maneiras de se preparar profissionais para transformar a escola, na perspectiva de uma abertura incondicional às diferenças e de um ensino de qualidade (MANTOAN, 2003, p. 82).

Ocorre que o processo de ensino-aprendizagem apresenta constantes desafios e diversas ressignificações, e as identidades dos professores também passam por esses processos. Passado o período de resistência inicial, o sentimento de alguns professores se torna antagônico na medida em que, por acreditarem que estão se esforçando para realizar um bom trabalho, concomitantemente existe uma angústia, ocasionada na maioria das vezes pela falta de um feedback positivo e incentivador de novas práticas e da real importância de seu papel.

Se de um lado, é preciso continuar investindo maciçamente na direção da formação de profissionais qualificados, de outro, não se pode descuidar da realização dessa formação e deve-se estar atento ao modo pelo qual os professores aprendem (MANTOAN, 2003, p. 82).

Tal situação requer atenção, não comodismo ou esquecimento, ou melhor, lembrar a cada passo, a cada olhar, que os profissionais envolvidos nisto, aqueles que estão em sala de aula, também precisam ser vistos como seres que necessitam ser atendidos em suas expectativas e demandas, para que possam realizar um trabalho de excelência.

Sabemos também que existe uma faceta neste processo que é a autonomia do professor em relação aos procedimentos didáticos que utiliza em suas aulas e com seus alunos, ao mesmo tempo, isso implica responsabilidade do professor. E talvez por isso, esses profissionais em algum momento se sentem acuados, pressionados, fossilizam métodos e acabam por cristalizar ideias e formas mais confortáveis.

A cristalização de hoje é a mudança que se operou ontem numa outra cristalização. Por isso é que nada de novo nasce em si mesmo, mas sim do velho que antes foi novo. Por isso também tudo que é novo, ao tomar forma, faz seu "testamento" ao novo que nascerá dele, quando esgotar e ficar velho (FREIRE, 1985, p. 47).

Todas essas questões somadas são capazes de mostrar que ainda se tornam necessárias algumas adaptações, mas o processo educacional é um exercício constante, amplo e cheio de sistematizações, sobre o que Mantoan (2003) afirma que o compartilhamento de ideias, sentimentos e ações entre o grupo de trabalho é ponto-chave do aprimoramento, pois é, através disso, das ações concretas e vivenciais, que existe a possibilidade das mudanças pretendidas e almejadas, ainda 
que advindas de processos anteriores ou ideias cristalizadas ou tidas como certas, existem outras formas e outros olhares.

É interessante reforçar que a proposta deste trabalho não possui a pretensão de estabelecer ou grifar apenas os aspectos negativos de uma proposta altamente válida e rica em seus valores. Muito menos responder de maneira cristalizada, a exemplo de alguns preceitos fossilizados no decorrer da história educacional, por aqueles que veem à mudança como instrumento desfavorável às regras vigentes em determinado momento, seja por comodismo, seja simplesmente para não ver contrariada uma sistematização que até então parecia lógica.

Ao pensar assim, surge à análise da posição que ocupamos e o que vem a partir disso, ou, apesar de, as inquietudes advindas das nossas ações ou daquilo que nos cerca, o universo em que se está inserido. "A sociedade é o palco da vida. Mas também é a rede da nossa trama. E o drama em que estamos enredados” (BARROS FILHO, 2010, p. 170).

Assim, por vezes, a vivência de um professor, torna-se um dilema antagônico existencial: "a trama e o drama", quando o espaço onde precisa desenvolver sua função e se adaptar a novas circunstâncias e as matrizes pedagógicas destoam da realidade que se apresenta. Nesse sentido, vários fatores foram observados no campo de análise: sala de aula lotada, cobrança incansável dos índices de reprovação, baixo aproveitamento escolar dos alunos. Somado a isso, a falta de preparo especializado.

Ocorre, que mediante a esses fatores, os professores, principalmente aqueles que atendem ao ensino médio, sentem-se em uma trajetória por caminho tortuoso e movediço. Afinal, as diferenças não estão presentes somente nos alunos, mas na caracterização da diversidade de pensamento e metodologia de ensino de cada profissional, um comportamento relativizado pela disciplina e, inevitavelmente, pela personalidade do profissional como ser, individualizado por emoções, perspectivas e habilidades próprias de interpretar a realidade, ainda que se esteja em campo fértil para as inovações.

\section{Caracterização das expectativas docente em relação à educação inclusiva}

Para além dos sentimentos de antagonismo existencial, os professores também relataram nos espaços de convívio diário, como reuniões pedagógicas e conversas informais na sala dos professores, expectativas em relação ao processo de inclusão escolar. A formação docente apareceu como uma das principais fontes nesse sentido, inclusive para dirimir o próprio antagonismo.

Ocorre que os cursos de graduação, os cursos de especialização, e até mesmo os projetos formadores, passaram a ser intensificados após a estruturação legal, mesmo assim, de forma tímida e contida. Mesmo atualmente, a rigor, nos cursos de graduação, a atenção é voltada somente para a aprendizagem muito introdutória da Libras e os demais conhecimentos necessários não compõem o currículo, salvaguardando poucas exceções.

Nas formações oferecidas pelo Estado de Minas Gerais, nem sempre é possível visualizar e vivenciar as condições do cotidiano escolar, o que acaba por acarretar uma série de apreensões, ansiedades e expectativas nos professores, somadas à questão do investimento nos professores, que é praticamente inexistente ou inócuo. Ocorrem também as reuniões pedagógicas, denominadas de Módulo I e II, que pouco auxiliam na solução desses conflitos.

Problemas conceituais, desrespeito a preceitos constitucionais, interpretações tendenciosas de nossa legislação educacional e preconceitos distorcem o sentido da inclusão escolar, reduzindo-a unicamente à inserção de alunos com deficiência no Ensino Regular. [...] Estamos diante de avanços, mas de muitos impasses da legislação (MANTOAN, 2003, p. 35).

Assim, o que se observou é que, independentemente das inovações, existe e insiste uma velha forma de ensinar. O currículo ainda é estruturado por disciplinas que definem os saberes e 
a sequência didática em que devem ser ensinados, coexistindo um padrão curricular que mantém verdades absolutas e prontas, quase imutáveis, de que a transmissão do conhecimento está na divisão dos conhecimentos, na reprodução dos modos, tanto do ensino como da aprendizagem (MANTOAN, 2003, p. 47-49).

De acordo com Demo (2002, p. 136), “[...] reconstruir não pode reduzir-se a repor tal qual havia antes. Implica desbordar os limites do dado. Não se trata apenas de rearrumar, mas de, sabendo desarrumar, arrumar de outra forma, de tal sorte que o processo determina resultados criativos". E é disso que os professores precisam; é isso que eles demandam.

Seria fácil, se difícil não fosse, já que, ao lidar com pessoas, o sentir, a cultura, o meio influenciam na forma como cada um vai conseguir superar suas deficiências no modo de agir, e, no caso dos professores, como lidar com o manejo do conhecimento e conseguir estabelecer uma dinâmica adequada em que ocorra aprendizagem por parte do aluno, e não apenas uma reprodução.

Segundo Santos (1995 Apud MANTOAN, 2003, p. 34), “[...] é preciso que tenhamos o direito de sermos diferentes quando a igualdade nos descaracteriza e o direito de sermos iguais quando a diferença nos inferioriza". Mantoan (2003) complementa ao dizer que a inclusão por plural, transgressora e democrática, deveria provocar uma crise de identidade institucional, que, por sua vez, abalaria também a identidade dos professores e ressignificaria a identidade do aluno.

Essa tarefa envolve a associação entre teoria e prática e, mais que isso, uma reflexão sobre a atuação profissional. Para tanto, é necessária uma reformulação nos currículos dos cursos de formação de professores, visando a preparação de profissionais competentes para lidar com os aspectos educacionais específicos das deficiências (DE MASI, 2008, p. 77).

Junto a isso, como pano de fundo, existe todo um aparato legal, que deve ser cumprido. Porém, De Masi (2008) faz um grifo muito interessante quando diz que "[...] inclusão não se faz por decreto". É um processo que demanda tempo e implica mudanças estruturais na cultura, a construção de uma nova postura pedagógica, na vida social (DE MASI, 2008, p. 76). Como nos aponta a própria legislação, em que:

[...] é afirmado que uma educação de qualidade pode ser balizada tanto pelo desenvolvimento cognitivo como pelo desenvolvimento emocional e criativo do aluno, e se efetiva por meio de: oportunidades positivas de aprendizagem; investimento nos professores; ensino e avaliação baseados nas características e possibilidades de cada aluno; ambiente educacional acolhedor, seguro e saudável (UNESCO, 2005, p. 18; UNICEF, 2012 Apud PLETSCH SOUZA, 2017).

Assim, fica nítido que as demandas dos professores, na verdade, não passam tão somente por formação. Passam também por valorização da classe e pela construção de uma rede de suportes, que seja real e afinada com a realidade e demandas da escola. Temos consciência de que não é só de formação que nossos professores precisam. Se a inclusão não se faz somente de legislação, tampouco se faz somente de formação de professores.

Assim como nos aponta Gatti (2010), temos a consciência de que a educação vem enfrentando um paradoxo. "Por um lado, visa oferecer possibilidades de mudanças, por outro revela a obscuridade, em que quanto mais educação se oferece, mais os problemas sociais se avolumam" (KONKEL et al., 2015, p. 5779).

\section{Considerações finais}

Ao escrever este trabalho, como defensores da educação e da inclusão escolar, tinha-se a perspectiva de encontrar professores favoráveis e professores contrários ao paradigma da inclusão 
escolar, com ideias bem formadas e posicionamentos claros e objetivos sobre o tema. No entanto, não foi exatamente isso o que o campo de investigação nos mostrou.

Encontramos professores que se sentem impotentes e temerosos. Se, no passado, sentiam-se resistentes à ideia da inclusão, atualmente não se sentem mais assim. O contato com os alunos mostrou-lhes e provou-lhes a importância da inclusão escolar, não apenas como algo abstrato, mas como atitude de empatia e solidariedade, como direito real de todos.

Os sentimentos de antagonismo existencial observados nos professores reforçam a ideia de que houve uma cristalização desse processo, não possibilitando uma reconstrução real das identidades dos professores e do fazer cotidiano na sala de aula regular. Parece que, apesar de muito preocupados, eles não conseguiram se reinventar, ao mesmo tempo que não identificamos nenhum suporte que, de fato, os tivesse auxiliado nesse movimento. Nas palavras de Mário Sérgio Cortella (2016, p. 12), “[...] uma nova edição, revisada e ampliada do que somos hoje [...]”, é um movimento muito bem-vindo para um professor que se quer inclusivo.

Assim, foi possível identificar um deslocamento do antagonismo dos professores em relação à inclusão escolar, que passou da completa resistência inicial, aos sentimentos de ansiedade, angústia e impotência. $O$ fato de um indivíduo ser professor não o faz menos temerário, não obstante, também aprendiz. Assim, da mesma forma que se torna necessária a defesa dos direitos dos alunos, simultaneamente a formação dos professores e a audição de seus anseios e expectativas importam, para que ocorra uma sinergia que possa fortalecer as ações e as práticas pedagógicas, uma sincronia capaz de se constituir em uma real inclusão escolar sem que para isso se tenha receio das diferenças.

Em relação às expectativas docentes, elas foram expressas sob a necessidade de formação continuada. Assim, uma das opções para dirimir o antagonismo existencial dos professores é o fortalecimento da identidade docente, atrelada à formação docente e à construção de uma rede de suporte, de forma a proporcionar suporte real às práticas pedagógicas.

\section{Referências}

ABBAGNANO, Nicola. Dicionário de Filosofia. Tradução de Alfredo Bosi e Ivone Castilho Benedetti. São Paulo: Martins Fontes, 2007.

ALVES, Paola Biasoli; KOLLER, Sílvia Helena; SILVA, Aline; REPPOLD, Caroline; SANTOS, Clarisse; BICHINHO, Gabriela; PRADE, Luciano; SILVA, Milena; TUDGE, Jonathan. A construção de uma metodologia observacional para o estudo de crianças em situação de rua: criando um manual de codificação de atividades cotidianas. Estudos de Psicologia, Campinas, v. 4, n. 2, p. 289-310, nov. 1999.

BARROS FILHO, Clóvis; MEUCCI, Arthur. A vida que vale a pena ser vivida. Petrópolis: Vozes, 2010.

BATISTA, Cecília Guarnieri. Observação do comportamento. In: PASQUALI, Luiz (org.). Teoria e métodos de medida em ciências do comportamento. Laboratório de Pesquisa em Avaliação e Medida, Instituto de Psicologia, Brasília, DF: UnB: INEP, p. 393-425, 1996.

BRAGA, Sheila Mayzanyela. Educação Especial: as Dificuldades Encontradas no Ambiente Escolar para a Inclusão. Só Pedagogia. São Paulo. Disponível em: http://www.pedagogia.com.br/artigos/asdificuldadesdainclusao. Acesso em: 10 maio 2020.

BRASIL. Lei de Diretrizes e Bases da Educação Nacional. Lei n 9.394, de 20 de dezembro de 1996. 5. ed., Brasília, DF: Casa Civil, 2010.

BRASIL. Saberes e práticas da inclusão: desenvolvendo competências para o atendimento às necessidades educacionais especiais de alunos com altas habilidades/superdotação. 2. ed., Brasília, DF: MEC, Secretaria de Educação Especial. Disponível em: http://portal.mec.gov.br/seesp/arquivos/pdf/altashabilidades.pdf. Acesso em: 20 fev. 2020.

CORDAZZO, Sheila Tatiana Duarte; WESTPHAL, Josielly Pinheiro; TAGLIARI, Fernanda Balem; VIEIRA, Mauro Luis; OLIVEIRA, Ana Maria Faraco de. Metodologia Observacional para o Estudo do Brincar na Escola. Avaliação Psicológica, Campinas, v. 7, n. 3, p. 427-438, 2008. 
CORTELLA, Mario Sergio. Filosofia: e nós com isso? Petrópolis: Vozes, 2019.

CORTELLA, Mario Sergio. Não nascemos prontos! Provocações filosóficas. 4. ed. Petrópolis: Vozes, 2006.

CORTELLA, Mario Sergio. Por que fazemos o que fazemos?!: Aflições vitais sobre trabalho, carreira e realização. 34. ed. São Paulo: Planeta, 2016.

CUNHA, Celso Ferreira da; CINTRA, Luís Filipe Lindley. Nova gramática do português contemporâneo. Rio de Janeiro: Nova Fronteira, 2001.

DE MASI, Ivete. Em busca de caminhos para a concretização das políticas públicas de inclusão. Revista @mbiente Educação, São Paulo, v. 1, n. 2, p. 68-78, ago./dez. 2008. Disponível em: http://arquivos.cruzeirodosuleducacional.edu. br/principal/old/revista_educacao/pdf/volume_2/rev_n2_6_de_masi.pdf. Acesso em: 12 abr. 2020.

DEMO, Pedro. Complexidade e Aprendizagem: a dinâmica não linear do conhecimento. São Paulo: Atlas, 2002.

FREIRE, Paulo. Educação e Mudança. 9. ed. Rio de Janeiro: Paz e Terra, 1985.

GATTI, Bernadete. Formação de Professores no Brasil: Características e Problemas. Educação \& Sociedade. Campinas, v. 31, n. 113, p. 1355-1379, out./dez. 2010. Disponível em: https:/www.scielo.br/j/es/a/R5VNX8SpKjNmKPxxp4QMt9M/?lang=pt\&format=pdf Acesso em: 09 maio 2020.

GOLEMAN, Daniel. Inteligência emocional: a teoria revolucionária que redefine o que é ser inteligente. Rio de Janeiro: Editora Objetiva, 2012.

GUIRALDELLI JUNIOR, Paulo. História da Educação Brasileira. 2. ed. São Paulo: Cortez, 2006.

HEIDEGGER, Martun. Ser e Tempo. 15. ed. Rio de Janeiro: Vozes, 2005.

KONKEL, Eliane Nilsen; ANDRADE, Cleudane; KOSVOSKI, Deysi Maia Clair. As Dificuldades no Processo de Inclusão Educacional no Ensino Regular: a visão dos professores do ensino fundamental. In: XII CONGRESSO NACIONAL DE EDUCAÇÃO. Anais [...]. Porto Alegre: PUC-RS, out. 2015.

LIBANIO, João Batista. Ideologia e Cidadania. São Paulo: Moderna, 1995.

MANTOAN, Maria Teresa Eglér. Inclusão escolar: o que é? Por quê? Como fazer? São Paulo: Moderna, 2003.

MENDES, Ericéia Gonçalves. Sobre alunos “incluídos” ou “da inclusão”: reflexões sobre o conceito de inclusão escolar. In: VICTOR, Sonia Lopes; VIEIRA, Alexandro Braga; OLIVEIRA, Ivone Martins de (org.). Educação especial inclusiva: conceituações, medicalização e políticas. Campos dos Goytacazes: Brasil Multicultural, 2017. p. 60-83.

PERRENOUD, Philippe. Construir as competências desde a escola. Porto Alegre: Artmed, 1999.

SALA, Marcos Elias; MORENO, Kênia Santos; DUARTE, Amanda Aparecida Pereira. Limites e possibilidades do Atendimento Educacional Especializado numa escola de tempo integral. Cadernos do Aplicação, v. 33, n. 1, Porto Alegre: UFRGS, 2020.

SAVIANI, Dermeval. Educação Brasileira: estrutura e sistema. 9. ed. Campinas: Autores Associados, 2005.

SOUZA, Flavia Faissal de; PLETSCH, Marcia Denise. A relação entre as diretrizes do sistema das nações unidas (ONU) e as políticas de educação inclusiva no brasil. In: Revista Ensaio: aval. pol. publ. Educ., v. 25. Rio de Janeiro, 2017.

TARDIF, Maurice. Saberes docentes e formação profissional. 17. ed., Petrópolis: Vozes: 2012.

UNESCO. Declaração De Salamanca: sobre princípios, políticas e práticas na área das necessidades educativas especiais. Conferência Mundial sobre Necessidades Educativas Especiais. Salamanca, Espanha, jan. 1994. Disponível em: http:// portal.mec.gov.br/seesp/arquivos/pdf/salamanca.pdf. Acesso em: 05 ago. 2021.

UNESCO. Declaração Mundial sobre Educação para Todos. Conferência de Jomtien. Tailândia, 1990. Disponível em: http://www.direitoshumanos.usp.br/index.php/Direito-a-Educa\%C3\%A7\%C3\%A3o/declaracao-mundial-sobre-educacao-para-todos.html. Acesso em: 02 fev. 2020.

WEISZ, Telma; SANCHEZ, Ana. O diálogo entre o ensino e a aprendizagem. 2. ed. São Paulo: Ática, 2002. 